\title{
A dimensão pedagógica da pesquisa nos cursos de Biblioteconomia do Mercosul: reflexões sobre uma trajetória de harmonização curricular
}

\author{
The pedagogical dimension of the research in \\ Mercosul's Library Studies courses: Reflections on \\ a trajectory towards curricula harmonization
}

Mara Eliane Fonseca RODRIGUES ${ }^{1}$

José Augusto Chaves GUIMARÃES²

RE S U M O

Partindo da concepção de pesquisa como mola mestra para um ensino de qualidade e considerando-se o fato da mesma constituir uma das áreas curriculares acordadas para os cursos de Biblioteconomia do Mercosul, analisam-se, sob uma ótica histórica, as concepções de pesquisa desenvolvidas no âmbito dos Encontros de Diretores e Docentes de Biblioteconomia do Mercosul (Porto Alegre, 1996; Buenos Aires, 1997; Santiago do Chile, 1998, Montevidéu, 2000 e Assunção, 2001) como subsídios ao delineamento de políticas de pesquisa para a graduação em Biblioteconomia no Mercosul. Com tal objetivo, este trabalho parte da reflexão teórica sobre pesquisa no ensino (em especial, no ensino de Biblioteconomia) para, a seguir, analisar a evolução das discussões da área curricular 6 - Investigação - levadas a cabo no âmbito dos referidos eventos.

Palavras-chave: pesquisa, ensino de Biblioteconomia, Mercosul.

\footnotetext{
${ }^{1}$ Bacharel em Biblioteconomia pela UFSC. Mestre em Ciência da Informação pela UFRJ/IBICT. Docente do curso de Biblioteconomia da Universidade Federal Fluminense (UFF). E-mail: mara@proac.uff.br

${ }^{2}$ Bacharel em Biblioteconomia. Mestre eDoutor em Ciência da Informação pelaECA-USP. Docente do curso de Biblioteconomia da Universidade Estadual Paulista (UN ESP) Marília. E-mail: jaguima@terra.com.br

Recebido e aceito para publicação em 8/7/2003.
} 


\title{
A B S T R A C T
}

\begin{abstract}
Departing from the conception of research as a springboard to a good quality teaching, and from the fact that research constitutes an elected subject in the approved curricula for Mercosul's Library Studies courses, this paper analyses, from an historical point of view, the research conceptions developed during the Mercosul Meetings of the Library Studies' Program Administrators and Teachers -Encontros de Diretores e Docentes de Biblioteconomia (Porto Alegre, 1996; Buenos Aires, 1997; Santiago do Chile, 1998; Montevidéu, 2000; and Assunção, 2001). Such conceptions may be taken as subsidies for designing research policies for the Mercosul Library Studies undergraduate program. Therefore, besides the theoretical analysis of research articulated with teaching practices (especially in Library Studies education), this paper analyses the very development of the discussions related to the curriculum area 6 -Research-, that took place during the mentioned events.
\end{abstract}

Key words: undergraduate program, research policies, curriculum, Library Studies, Mercosul.

\section{N T R O D U C Ã O}

As sociedades atravessam um período de intensas mudanças, com a ruptura de inúmeros paradigmas que, ao longo do último século, direcionaram o desenvolvimento social e econômico. Essas mudanças produziram o redesenho da cartografia mundial, e tanto nações, quanto organizações e indivíduos, buscam ainda seu referencial em novo centro de equilíbrio.

Pensar em fazer uma análise do século XX, talvez seja cedo, tantas foram as mudanças operadas. Entretanto, percebe-se que as modificações produzidas pela revolução dos costumes e pelo vertiginoso avanço da ciência e da tecnologia continuarão a marcar fortemente a sociedade do século XXI.

Nesse contexto, a universidade, enquanto instituição social, não aparece diferenciada e, sob tensões, busca enfrentar a crise que caracteriza nossa época e que a atinge, traduzindo-se no questionamento de seu papel e de seu desempenho.

\section{Universidade: contextos, mudanças e impactos}

No Brasil, devido as circunstâncias históricas, a idéia de universidade, desde a sua gênese, enfrenta dificuldades que se prendem a inúmeros fatores. No caso brasileiro, a conjuntura deixou marcas na estrutura. Por longo tempo, observou-se na educação superior brasileira uma tendência: a de ser voltada exclusivamente às profissões liberais, de caráter prático e de sentido dominantemente utilitário.

A partir da mudança de condições da sociedade brasileira em vias de ser transformada pela revolução industrial e tecnológica, o ensino superior passou a defrontar-se com problemas, levando o Estado a examinar a estrutura das universidades e reestruturar o ensino universitário. Desde então, a universidade brasileira passou por alguns planos de reestruturação, sendo o mais marcante deles a Reforma de 1968, cujas conseqüências fazem-se presentes até os dias de hoje.

Atualmente, o sistema de ensino superior brasileiro é heterogêneo e está representado por dois modelos: um predominantemente transmissor de conhecimento, comum às não-universidades e a alguns setores das universidades privadas, e outro; produtor de conhecimento, presente nas universidades públicas.

Ao despontar de um novo século, a universidade brasileira vê-se mais uma vez diante 
de pressões para modificar-se, chegando alguns a afirmar que atravessa um período de crise endêmica. Chega-se a propor que a saída da crise se faça por um mergulho nela mesma, porque se acredita que "em vez de temer a crise, a universidade precisa aproveitar-se dela. $\mathrm{Na}$ crise, terá a justificativa de seu papel" (BUARQUE, 1994).

$\mathrm{Na}$ realidade, a crise tantas vezes mencionada, não é localizada, mas mundializada e, sobretudo, institucional. A solução não estará na ocorrência, nem na dependência de procedimentos normatizados. A saída da crise poderá estar nas possibilidades que se oferecerem à universidade-instituição de conseguir compatibilizar tradição e adaptação às novas configurações e demandas sociais, e liberar-se das tensões que têm origem nessa contradição.

Imagina-se que uma das maneiras de viabilizar a adaptação aos novos contextos dar-se-á via definição de projetos que possam dar novos contornos ao ensino superior. Essa proposta teria seu ponto inicial em uma mudança de concepção que se estruturou até então pelo paradigma da modernidade, trabalhando 0 conhecimento muito mais como produto do que como processo.

Hoje, percebe-se no ensino superior uma tendência para ver e entender o conhecimento como processo. Esta inclinação altera as formas metodológicas que são usadas no modo tradicional de transmissão e repetição para que o estudante retenha um conhecimento em estoque, disponível ao uso quando em exercício profissional. No desenvolvimento do conhecimento como processo, a perspectiva metodológica coloca, para a universidade, desafios em fazer com que se renovem e se resignifiquem como eixo pedagógico a indissociabilidade do ensino com a pesquisa e a extensão.

A atribuição do mesmo grau de importância ao ensino, à pesquisa e à extensão passa, portanto, pela investigação de novas formas de transmitir e produzir conhecimento no processo de formação, o que seria dizer que, também, faz-se necessário identificar de que instrumentos metodológicos a universidade dispõe e pode colocar em prática.

Não se deve esquecer que todo exercício profissional se dá em um tempo e em um lugar determinados, em estreita relação com projetos que podem fechar ou abrir os horizontes humanos. Todo saber é contextualizado historicamente, assim como toda atividade profissional humana se dá em contexto social, portanto, a aquisição de conhecimentos deve ir para além da aplicação imediata e impulsionar o sujeito, em sua dimensão individual e social, a criar e responder a desafios.

\section{A pesquisa como cotidiano didático do professor e do aluno}

A perspectiva acima colocada, exige uma nova visão e um novo paradigma de educação superior que tenha seu interesse centrado no estudante. Essa compreensão permeia e altera as práticas tradicionais de ensinar e aprender, ainda vigentes na universidade. A lógica que trespassa o ensino tradicional, o concebe como um processo mecânico, repetitivo e fragmentado. Nesta lógica, o conhecimento é visto como algo pronto e acabado, verdade absoluta, externa ao aluno e que deve ser nele inculcada para, depois de memorizada, ser reproduzida, avaliada e utilizada.

A concepção de ensino e aprendizagem que tem o aluno como centro do processo, exige dele capacidades e competências diferentes. Ao invés de memorização, solicita capacidade de interpretação, de julgamento de sentido e de relação com o social e o vivido. Do professor exige novas aproximações didáticas e pedagógicas, a fim de facilitar a aquisição de conhecimentos práticos, competências e habilidades para a comunicação, análise criativa e crítica e reflexão independente. 
Para alcançar essas metas, a educação superior deve utilizar-se de novos e apropriados métodos que permitam ir além do domínio cognitivo de conteúdos. A aprendizagem deve ser interpretada como um caminho que possibilita ao sujeito social (aluno) transformar-se e transformar seu contexto.

Essa visão de ensinar e aprender busca a formação integral e adequada do estudante através de uma articulação entre o ensino e a pesquisa, tendo a investigação como eixo integrador dos conteúdos curriculares e parte do pressuposto de que pelo ensino também se faz produção de conhecimento.

Para isso, questão absolutamente fundamental é tornar a pesquisa o ambiente didático cotidiano, no professor e no aluno, para desfazer a idéia de que pesquisa é uma atividade especial que somente pode ser desenvolvida por gente especial (DEMO, 1997).

A educação pela pesquisa, significa aprender a ler a realidade de modo questionador e de reconstruí-la como sujeito competente, o que, de acordo com Demo (1997, p.10), leva ao questionamento reconstrutivo. Isso não significa, no entanto, que o professor deixará de trabalhar com os alunos noções básicas dos contextos e dos métodos de investigação usados pelas diferentes ciências, pois para analisar a realidade de modo crítico é importante conhecer e saber usar determinados procedimentos comuns aos utilizados na investigação científica: registro, sistematização de informações, análise e comparação de dados, verificação, etc.

Na visão de Demo (1997, p.33), para desenvolver no aluno a habilidade questionadora reconstrutiva é necessário que o professor o oriente permanentemente para:

a) expressar-se de maneira fundamentada - explicar ao aluno que o discurso acadêmico difere dos outros, porque questiona com lógica e argumentação;

b) exercitar o questionamento-exigir que toda investigação seja realizada de forma sistematizada, ou seja, não vale procurar materiais sem método, colher dados sem organizá-los, citar sem contraler, entre outros;

c) exercitar a formulação própria - fazer bom uso da lógica, da argumentação, da crítica e da autocrítica, dentro da regra segundo a qual só se pode garantir o que de alguma forma tem base; não adianta construir algo que ninguém mais pode decifrar, ou usar linguagem particular inacessível;

d) reconstruir autores e teorias - incitar a reconhecer nos outros (autores, pesquisadores, professores) os procedimentos criativos que indicam a capacidade de questionar e reconstruir, não para imitar mas, sob o estímulo do exemplo, encontrar pistas da criatividade própria;

e) cotidianizar a pesquisa - tornar o questionamento reconstrutivo uma atitude cotidiana, de modo a tornar o ambiente acadêmico naturalmente positivo e estimulante, no qual a leitura constante é algo normal, a feitura de trabalho próprio é óbvia, o esforço de equipe bem organizado e produtivo é exigência evidente.

Por outro lado, para trabalhar dessa maneira o professor precisa continuamente fazer ajustes entre o que planeja ou prevê e aquilo que acontece na interação com os alunos. Boa parte dos ajustes têm que ser feitos em tempo real ou em intervalos relativamente curtos, sob risco de passar a oportunidade de intervenção no processo de ensino e aprendizagem. Ensinar requer dispor e mobilizar conhecimentos para improvisar, intuir, atribuir valores e fazer julgamentos que fundamentem a ação mais pertinente e eficaz possível.

Por essas razões, o professor, como profissional da educação, deve ser também um pesquisador. Contudo a pesquisa (ou investigação) que se desenvolve no âmbito do trabalho do professor não pode ser confundida com a pesquisa acadêmica ou científica. Refere-se, antes de mais nada, a uma atitude cotidiana de 
busca de compreensão dos processos de aprendizagem e desenvolvimento de seus alunos e à autonomia na interpretação da realidade e dos conhecimentos que constituem seus objetos de ensino.

$\mathrm{Na}$ universidade, a idéia de fazer da pesquisa um cotidiano didático, tanto para o professor, como para o aluno, precisa ser trabalhada para que a articulação ensino/pesquisa realmente se efetive. Para isso, será fundamental que se tenha coragem de alterar consistentemente a lógica dos currículos vigentes, onde a dissociação entre a teoria e a prática gera desinteresse e falta de sentido para a vida dos acadêmicos. Para isso, a prática da pesquisa deve estar presente em todos os momentos da formação universitária, conjugando reciprocamente teoria e prática. A perspectiva do ensino articulado à pesquisa constitui-se, então, em um componente essencial para impulsionar uma resignificação da atitude de ensinar e aprender na universidade.

Desse modo, faz-se necessário repensar o processo de construção do conhecimento na universidade, buscando-se educar pela pesquisa, tendo em vista um perfil de profissional-cidadão de quem se espera competência e não somente reprodução do saber. Para tanto, há de se voltar esforços para aquilo a que Demo (1997, p.128) se refere como "aprender a aprender", em um processo educativo e emancipatório, permitindo o diálogo crítico e criativo com a realidade, a fundamentação de um ensino não mais meramente repasse copiado, e a convivência mutuamente enriquecedora entre teoria e prática.

$\mathrm{Na}$ Biblioteconomia, como em tantas outras áreas do conhecimento, tal cenário encontra reflexos marcantes, em um momento que se procura romper com uma concepção de profissional eminentemente técnico para se buscar um perfil de natureza mais interdisciplinar, que possa dar conta de uma realidade heterogênea, em um mundo globalizado, com usuários mais exigentes e todo um aparato tecnológico em constante aperfeiçoamento.

Nesse contexto, a exigência de profissionais com maior amplitude de conhecimentos e habilidades trouxe à universidade uma reflexão fundamental: a necessidade de se formar profissionais inovadores, críticos e teoricamente embasados que pudessem não mais se limitar $a$ atender às exigências de um mercado em constante mudança mas, indo além, criar novas demandas e especificidades para esse mercado.

Como bem assevera Dosa citada por Mueller (1989, p.176), uma profissão é composta de três elementos: a prática da profissão, o sistema de educação e treinamento profissional e a pesquisa, que visa contribuir para o desenvolvimento da área. Indo além, pode-se dizer que a pesquisa atua como mola mestra da prática profissional e do sistema educativo, haja visto seu componente de questionamento aliado aos parâmetros de cientificidade, permitindo um efetivo ir além.

Desse modo, ressaltam Guarido, Guimarães e Oliveira (2001) que aos cursos de Biblioteconomia cabe, agora, um desafio, que está na produção de conhecimento próprio, constituindo-se a pesquisa, enquanto princípio científico e educativo, a alma da vida acadêmica.

Tais aspectos encontram-se presentes nas pauta de discussões do grupo de escolas de Biblioteconomia do Mercosul, no âmbito da qual a Investigação figura como área curricular específica, como demonstram as discussões havidas nos cinco encontros até então realizados - Porto Alegre, 1996, Buenos Aires, 1997, Santiago do Chile, 1998, Montevidéu, 2000 e Assunção, 2001, que a seguir serão analisados.

\section{A pesquisa no âmbito dos estudos de harmonização curricular em Biblioteconomia no Mercosul}

As origens dos estudos curriculares em Biblioteconomia no Mercosul, pautam-se, como 
ressalta Guimarães (2000) por questões de natureza jurídica - a criação do Mercosul, pelo Tratado de Assunção, em cujo Programa III do Plano para o Desenvolvimento Educativo Regional do Mercosul observa-se o compromisso dos Ministérios da Educação dos países firmantes quanto a harmonização dos sistemas e busca de compatibilização acadêmica, jurídica e administrativa e o estabelecimento de um sistema comum de informação educativa relevante (SANTOS, 1997, p.3) - e de natureza didático-pedagógico-investigativa, quando a comunidade acadêmica da área resolve criar espaços mecanismos para identificação e análise da situação, na área, bem como para o delineamento de políticas conjuntas de ação.

Especificamente no âmbito didático-pedagógico-investigativo, que é objeto deste trabalho, há de se registrar, como antecedentes, os trabalhos levados a cabo no âmbito dos Encuentros de Educadores e Investigadores en Bibliotecologia, Archivologia, Ciencia de la Información y Documentación de Iberoamerica y el Caribe (EDIBCIC), iniciados em 1993, (San Juan de Porto Rico), mais voltados para a questão das perspectivas de educação a distância em Biblioteconomia na Ibero-América.

A partir do II Encontro (Cidade do México, 1995), o evento passou a ser operacionalizado por meio de três vertentes básicas - ensino de graduação, ensino de pós-graduação e pesquisa - que mantém até hoje, criando comissões inter-países.

Mas foi efetivamente no III Encontro (San Juan de Porto Rico, 1996) que a questão da pesquisa passou a ser objeto específico - e oficial - das estruturas curriculares da área, como bem se observa em uma das recomendações oriundas da Comisión de Pregrado (ENCUENTRO DE EDUCADORES E INVESTIGADORES..., 1996, p. 2-3) verbis: que las curriculas consideren asignaturas que logren una educación integral del estudiante de modo a que permitan: a) una formación general y basica, la cual debe responder a las necesidades específicas de la profesión y a las caracteristicas de cada universidad (cliclos básicos $u$ otros) y b) una formación especializada que cubra las seguientes áreas: Fundamentos teóricos de la Bibliotecología y Ciencias de la Información; Procesamiento de la Información; Recursos y Servicios de la Información; Tecnologia de la Información; Gestión de Unidades de Información; Investigación; y Práctica Profesional (asuntos académicos.

Tendo participado do evento, a então presidente da Associação Brasileira de Ensino de Biblioteconomia e Documentação (ABEBD), Jussara Pereira Santos, estabeleceu contato com os dirigentes de cursos universitários de Biblioteconomia da Argentina, do Uruguai e do Paraguai, e lançou as bases para a realização de um evento conjunto para discutir e estudar a questão de harmonização curricular na área. $\mathrm{Na}$ ocasião, embora não integrando o Mercosul, o Chile acenou com o interesse de integrar-se a tais estudos. Estavam pois, a partir daquele momento, lançadas as bases para algo que, nos anos seguintes iria se consolidar e gerar frutos, qual seja o Grupo de Estudos Curriculares em Biblioteconomia do Mercosul.

Desse modo, em setembro de 1996 teve lugar, em Porto Alegre, o I Encontro de Dirigentes de Cursos Universitários de Biblioteconomia do Mercosul $^{3}$, "marco referencial para a história do

\footnotetext{
${ }^{3} 0$ evento contou com a participação dos sete cursos universitários argentinos, um dos dois chilenos, do curso uruguaio e do curso paraguaio, assim como dos coordenadores dos grupos regionais de estudos curriculares da ABEBD e de vários dirigentes dos cursos de graduação brasileiros.
} 
ensino de Biblioteconomia latino-americano, visto permitir, pela primeira vez, uma discussão sistematizada sobre questões de ensino afetas ao segmento Mercosul" (GUIMARÃES, 2000).

Dentre os aspectos abordados no evento, no que tange à questão da pesquisa, destaque inicial deve ser dado às conferências-chave, "Ensino de graduação e pesquisa, Fontes de financiamento em Ciência e Tecnologia, e Moderno profissional da informação"4, visto trabalharem a temática respectivamente sob a ótica da inserção curricular, do fomento e da prática profissional.

No tocante às áreas curriculares, adotouse o recomendado na reunião de Porto Rico, com exceção da área de Prática profissional, entendida como uma vertente de cunho interno no âmbito das instituições, não propriamente uma área curricular em termos de conteúdo, visto que os mesmos perpassam os conteúdos de todas as demais. Desse modo, a Pesquisa passou a ser objeto, para o Mercosul, da área curricular 6.

Votou-se ainda pela institucionalização dos encontros como fórum oficial de discussão e deliberação de questões de ensino de Biblioteconomia do Mercosul, aprovando-se a periodicidade anual do evento, a realizar-se em revezamento, cada vez em um dos cinco países participantes.

Em termos de educação continuada dos docentes de Biblioteconomia, recomendou-se o desenvolvimento de oficinas de atualização de 3h cada, a serem desenvolvidas em São Luiz do Maranhão, durante o Congresso Brasileiro de Biblioteconomia e Documentação (jul. 1997), a partir de áreas de excelência identificadas no ensino de Biblioteconomia de cada país. Nesse sentido ao Brasil, dada sua experiência em pós-graduação e pesquisa, coube encarregar-se da oficina Pesquisa em Biblioteconomia.
Por ocasião do II Encuentro de Directores... teve lugar o I Encuentro de Docentes de Cursos Superiores de Bibliotecología del Mercosur (Buenos Aires, nov. 1997), ocasião em que se chegou à definição de ementas e de conteúdos mínimos, a partir de uma sistemática de seis grupos de trabalhos, por áreas curriculares. Tal resultado decorreu do estudo sistematizado de conteúdos de áreas, por país, realizado a partir de recomendação do evento anterior.

Como ponto de reflexão, Emílio Setién Quesada, da Biblioteca Nacional José Martí (Cuba), em sua conferência acerca das tendências atuais da metodologia em Biblioteconomia, alertou para a diversidade de embasamentos filosóficos tradicionalmente verificáveis na pesquisa da área, muitas vezes sem que se tenha consciência. disso

Desse modo, como resultado dos trabalhos do referido grupo, chegou-se à seguinte ementa geral (ENCUENTRO DE DIRECTORES...., 1997, p.2) para a área de Investigação:

Epistemologia da pesquisa científica. Metodologia da pesquisa social. Investigação em Biblioteconomia e Ciência da Informação: produção e comunicação científica.

Decorrendo dessa ementa geral, definiu-se que a área de Pesquisa deveria contemplar a transferência de conhecimentos teórico-metodológicos, conhecimentos instrumentais e seus exercício prático na realidade. Para tanto, em termos de capacitação teórico-metodológica, ressaltou-se a importância de uma base epistemológica e de metodologia da pesquisa, para os conhecimentos instrumentais, elementos mínimos de Estatística descritiva, Redação técnica e Computação e, no tocante à prática

\footnotetext{
${ }^{4} \mathrm{~A}$ cargo, respectivamente, de Solange Puntel Mostafa - (PUCCAMP), Marlene de Oliveira - (CNPq) e José Augusto Chaves Guimarães - (UNESP).
} 
de pesquisa, trabalhos que contemplassem tanto o desenvolvimento de projetos como sua efetivação, materializando-se em monografias e trabalhos de conclusão de curso sob a orientação de docentes.

Uma vez abordada a questão dos conteúdos curriculares, no III Encuentro de Directores Y II de Docentes de Escuelas de Bibliotecología del Mercosur, (Santiago do Chile, out. 1998), teve lugar a discussão das cargas horárias mínimas para viabilizar os conteúdos, bem como as competências do profissional almejado pelos cursos nas diferentes áreas. Especificamente no âmbito do grupo de trabalho relativo à área de Investigação, chegou-se à indicação de que a área seja responsável por uma carga horária em torno de $10 \%$ da carga total dos cursos. Na ocasião, enunciou-se, pela primeira vez, um entendimento que a delegação brasileira já desde o evento anterior vinha manifestando: a transver-salidade da Investigação e das Novas Tecnologias em relação às demais quatro áreas de conteúdo.

Em termos de objetivos para a área, definiu-se (ENCUENTRO..., 1999, p.174):

Incentivar o espírito e as atitudes de investigação bem como desenvolver as capacidades de comunicação científica por meio do conhecimento e da análise dos paradigmas e metodologias das ciências sociais, pautando-se nos distintos contextos regionais e tendo em vista a problemática da sociedade da informação.

Decorrendo da definição de tais objetivos, recomendou-se ainda para a área: o equilíbrio entre métodos quantitativos e qualitativos, e necessidade de se contemplar diferentes níveis para formação em pesquisa, com especial ênfase à geração de conhecimentos para a área, a importância da difusão dos resultados de pesquisa (no caso dos discentes, por meio de defesas de TCCs); a concepção da pesquisa como princípio educativo aplicável a todas as disciplinas e a implantação de um sistema de avaliação nas disciplinas da área que contemple a participação de consultores ad hoc no âmbito do Mercosul.

Dentre os trabalho apresentados, Rodrigues (ENCONTRO, 1999, 44) abordou a pesquisa como estratégia pedagógica visando à competência profissional, propondo o desenvolvimento de um programa regional de formação baseado na articulação da pesquisa com o ensino, com a função política de formar profissionais capazes de encaminhar idéias alternativas para as questões surgidas com os desdobramentos da revolução tecnológica e a globalização de mercados (p.43), programa esse pautado na cooperação acadêmica e na circulação da informação sobre projetos e pesquisas em desenvolvimento nas escolas. Para tanto, aborda-se a questão da investigação cooperativa para desvendar novas realidades.

Estando os conteúdos fundamentais de áreas e a operacionalização desses conteúdos nas estruturas curriculares - objetivos almejados e cargas horárias utilizadas - já devidamente discutidos, ao IV Encuentro de Directores Y III de Docentes de Escuelas de Bibliotecología del Mercosur $^{5}$ (Montevidéu, maio 2000) coube trabalhar com as bases conceituais e metodológicas do ensino de Biblioteconomia e Ciência da Informação, temática que por si só pressupunha uma abordagem da questão curricular sob uma ótica investigativa. Nesse sentido, e

\footnotetext{
5 Registra-se a realização, em Granada, Espanha, em fevereiro de 2002, do V ENCUENTRO DE EDIBCIC (Granada, 21-25 fev. 2000), no âmbito do qual vale destacar a realização da mesa-redonda Los Encuentros de Directores de Bibliotecologia del Mercosur (1996-2000): relato de una rica experiência regional en educación superior, integrada por representantes da Argentina, do Brasil, do Paraguai e do Uruguai, de modo a compartilhar a experiênica de compatibilização curricular até então trilhada pelos países do Mercosul com os demais colegas da Ibero-América.
} 
formalizando a figura do observador internacional, com participantes da Espanha e da Colômbia, o evento contou com conferências gerais em que já se contemplavam temáticas de cunho teórico-metodológico, tais como a dimensão científica, técnica ou tecnológica da Ciência da Informação (CONFORTI \& ARTAZA, 2000), as questões de inter e transdiciplinaridade na área (CHUEQUE et al., 2000) e a necessidade de uma metateoria para a área (SABELLI, 2000).

Indo além, as conferências específicas da área 6 (Investigação), a cargo de Fernández (2000) e Rodrigues (2000), trouxeram novos aportes á questão. Na primeira, discutiu-se o fato de a pesquisa em Ciência da Informação ser parte de uma prática institucional - que pode ser de privilégio ou de subordinação - alertando para a necessidade da área contemplar, por um lado, a pesquisa para dar respostas a problemas concretos e, por outro, aquela que abre espaço para debate teórico no meio acadêmico. A segunda, por sua vez, discutiu a necessidade de uma nova concepção pedagógica para o ensino de Biblioteconomia e Ciência da Informação que, fugindo da mera reprodução de conhecimentos, voltando seus olhos - e esforços - para o aprender com pesquisa, no sentido de caminhar para que a educação / formação seja realmente integrada, envlvendo estudantes e professores na tarefa de investigar e analisar seu próprio mundo (...) para construir uma proposta capaz de refletir uma intervenção transformadora e que promova novas posturas diante do mundo.

No âmbito das recomendações de área, o grupo de Investigação reiterou, com mais ênfase, a questão da transversalidade da investigação relativamente às demais áreas, uma vez que consiste muito mais em um processo. Ainda assim, os trabalhos do grupo ressaltaram marcos teóricos de duas ordens: geral, relativos aos paradigmas da própria Ciência da Informação, e específico, voltados para a metodologia da pesquisa social, com a preocupação de que os docentes das disciplinas de cunho metodológico buscassem referências concretas na área de Ciência da Informação ao mesmo tempo que os de áreas de conteúdo se preocupassem com a questão do aprendizado contemplando uma ótica investigativa.

Desse modo, o ensino com pesquisa foi recomendado como estratégia didática para a área, para o que se alertou para a necessidade de experiência investigativa pelos docentes, aspecto que potencializaria, ainda, uma maior vinculação teoria-prática seja por meio de tutorias e projetos interdisciplinares (envolvendo co-orientações), seja pelo esforço em apresentar os problemas práticos da área, relacionando a teoria com referenciais empíricos precisos (ENCUENTRO..., 2000, p.397). Para tanto, recomendou-se o aumento do quadro docente em dedicação exclusiva ao ensino e à pesquisa.

Identificada como área que recebe aportes teóricos de áreas como Epistemologia, Estatística, Psicologia, Sociologia, Antropologia Cultural, Linguística, História, Filosofia de Ciência, Educação, Ciência Política e Economia, dentre outras, ressaltou-se a necessidade de sua articulação com a extensão universitária, com especial destaque a aspectos como a celebração de convênios com distintos setores da sociedade, oferecimento de bolsas de pesquisa a estudantes e docentes (para o que se enfatizou a necessidade de consolidação da informação sobre fontes de financiamento à pesquisa no Mercosul), e previsão de canais de divulgação dos resultados de pesquisa (como as homepages institucionais, por exemplo).

Completando o ciclo, ao Paraguai coube sediar o V Encontro de Diretores e IV de Docentes, com a peculiaridade de contar com a participação da Bolívia, ainda como candidato a integrar-se ao grupo, bem como com a participação de observador internacional da Espanha. Desse modo, e uma vez discutidos os pontos mais ligados às questões curriculares, os eventos centraram sua abordagem na figura do 
docente (aqui entendido como um docente-investigador), tendo como temas respectiva-mente as Diretrizes político-estratégicas para uma formação docente com impacto na pesquisa e na extensão e o docente de Biblioteconomia na sociedade do conhecimento, enfocando o novo perfil docente, a ética como responsabilidade social na atividade educativa e as inovações exigidas pelos novos tempos.

O evento teve como objetivos analisar as características do docente de Biblioteconomia para a formação da sociedade do conhecimento, refletir, compreender e atuar sobre a prática docente com o objetivo de transformação social, favorecer a inovação educativa nas Escolas de Biblioteconomia do Mercosul e contribuir para o delineamento do perfil do docente de Biblioteconomia e Ciência da Informação.

No âmbito do Encontro de Diretores, como bem ressalta Oliveira (2001, p.1)

Cabe o destaque dos trabalhos, ao quadro comparativo traçado sobre o exercício docente nos países do Mercosul, no qual se considerou as semelhanças e diferenças entre os diversos países segundo os seguintes indicadores: requisitos para ascender à docência, (concursos, exames etc...), mecanismos de promoção docente, aspectos legais do exercício da docência, otimização do trabalho docente $\mathrm{e}$ avaliação do desempenho docente. Assim, foram comparados e unificados estes critérios e tiradas as recomendações, estas aprovadas na reunião com os docentes.
Desse modo, pela primeira vez se teve uma idéia mais abrangente da realidade docente na região, aspecto que permitiu a discussão de perspectivas de intercâmbio e de programas conjuntos futuros.

No âmbito das conferências gerais, bastante presente se fez a discussão da pesquisa como uma necessidade básica para o docente, desde reflexões mais abarcativas sobre o papel docente rumo a uma sociedade do conhecimento ${ }^{6}$ e os impasses e perspectivas da própria prática pedagógica na área, no contexto atual ${ }^{7}$ até outras mais diretamente ligadas à questão da pesquisa no ensino e do ensino pela pesquisa ${ }^{8}$.

Tais aspectos encontraram reflexo direto no grupo 6 (Investigação), como se observa pelo teor do trabalho apresentado por Moreira, Guimarães e Oliveira (2001) trouxe uma reflexão a partir da uma experiência concreta de ensino pela pesquisa no âmbito da Biblioteconomia, quando a questão da iniciação científica foi assumida como elemento norteador de toda uma estrutura curricular.

Nas conclusões do trabalho do referido grupo, mais uma vez ficou o corte transversal que a Pesquisa efetua na área de Biblioteconomia e de Ciência da Informação, devendo ser objeto de incorporação pela atividade docente nas distintas áreas temáticas. Igualmente se reafirmou a indissociabilidade entre ensino e pesquisa, visto que a pesquisa, enquanto verdadeiro princípio educativo, fundamenta o ensino, e evita que aquele se transforme em mero repasse de conhecimentos ou que se desenvolva à revelia da realidade social. Como paradigma fundamental tem-se, pois, a possibilidade de o aluno desenvolver sua capacidade de intervenção na realidade social,

\footnotetext{
${ }^{6}$ QUINTANA DE HORÁK, Carmen. El docente para la sociedad del conocimiento.

7 LEÓN DE ALEGRE, Sonia. Innovación Educativa e ORTíZ DE CARDOZO, Gloria. Formar para innovar.

8 RODRIGUES, Mara Eliane Fonseca. A docência universitária e os desafios do mundo moderno: reflexoes sobre a prática pedagógica do docente de Biblioteconomia ; AYALA RODRÍGUEZ, María Soledad. Incorporación de la investigación en la for mación de profesionales; eESCOBAR DE MOREL, Margarita. La función docente integrada a la extensión y la investigación.
} 
aspecto que lhe confere elementos para desenvolver sua autonomia crítica, criativa e competente.

A assunção da pesquisa como princípio educativo passa a exigir, do docente, uma constante renovação, pois de mero transmissor de conhecimentos passa a assumir um papel de orientação em um contexto de construção conjunta de conhecimento. Tais aspectos levam à necessidade de uma nova figura docente, para o qual devem convergir esforços institucionais que lhe propiciem: constante requalificação (em termos de conteúdo e em termos metodológicos), tempo integral de trabalho, e a devida infra-estrutura universitária (física, bibliográfica e tecnológica).

E os reflexos desse contexto devem ser tenazmente perseguidos por meio de uma nova postura docente que se consubstancie nas seguintes estratégias:

- estimular práticas de estudo independente,

- encorajar o aproveitamento do conhecimento, habilidades e competências,

- desenvolver projetos de pesquisa integrados com temáticas curriculares,

- trabalhar em regime de tutoria e co-orientação nos projetos com caráter interdisciplinar,

- trabalhar em equipe,

- encorajar as experiências profissionais julgadas relevantes para a área;

- integrar os conteúdos curriculares ao contexto histórico-social, utilizando formas variadas de ensinar, buscando a participação do aluno;

- fortalecer a articulação da teoria com a prática, valorizando a pesquisa individual e coletiva, como também o desenvolvimento de atividades complementares, tais como: participação em seminários e congressos, visitas programadas e outras atividades acadêmicas e culturais, igualmente orientadas;

- otimizar o uso de técnicas socializantes.

\section{O N C L U S Ã O}

Como se pode observar, nesse momento em que se inicia uma nova fase dos estudos de harmonização curricular na área, no Mercosul, desloca-se - ou, melhor dizendo, aperfeiçoa-se - o foco de discussão, da análise da estrutura curricular para os agentes do processo ensino/ aprendizagem na área, fazendo emergir, com a ênfase que estes novos tempos exigem, a questão da pesquisa no ensino, aspecto que levou à definição deste VI Encontro de Diretores e $\mathrm{V}$ de Docentes de Biblioteconomia e Ciência da Informação do Mercosul, tendo como tema a própria questão da Pesquisa nos cursos de Biblioteconomia e Ciência da Informação da região, mais especificamente no que tange a suas relações com o ensino e a extensão, envolvendo aspectos como: Pesquisa Docente, Pesquisa Discente, Linhas e Grupos de Pesquisa, Formas de Apoio e Fomento a Pesquisa, Programas e Políticas Institucionais de Pesquisa, A Pesquisa no Ensino e o Ensino da Pesquisa, A Pesquisa e a Extensão / Serviços à Comunidade; A Pesquisa como Forma de Integração entre a Graduação e a Pós-Graduação; a Base Científica do Fazer Acadêmico e as Estratégias de Efetivação da Pesquisa enquanto Elemento Permeador do Processo Educacional.

Desse modo, e uma vez assumida a pesquisa como mola mestra do processo educativo na área, mormente em um contexto de constantes mudanças tal como ora nos apresenta, acredita-se que a sua discussão em moldes mais específicos e operacionais tal como se propõe o referido evento, poder-se-á pensar, 
a médio (ou mesmo a curto) prazo no delineamento de políticas integradas que permitam ao ensino de Biblioteconomia e Ciência da Informação um efetivo salto de qualidade, pela geração de conhecimento próprio, comprometido com a realidade social mas não menos afinado com os parâmetros e os avanços científicos da área em âmbito internacional.

Além disso, ao tomar como compromisso formar profissionais de informação através da educação pela pesquisa, a área, na realidade, está tomando a decisão de deslocar o futuro para o presente enfrentando os problemas estruturais que atingem o ensino de Biblioteconomia e Ciência da Informação (conteúdos curriculares voltados para a racionalidade instrumental - funcional - imediata - adaptativa) de forma renovada.

Ao recuperar a relação entre ensino e pesquisa, os educadores da área assumem que pelo ensino também se faz produção do conhecimento, incluindo, no cerne desse processo, a produção da consciência das novas gerações, fazendo-os sujeitos da própria história, capazes de enfrentar com independência e cidadania os desafios que se avizinham em um mundo tecnológico e globalizado, principalmente, no contexto econômico-político-social dos países que integram o Mercosul.

\section{RE FERÊ N C I A S}

ASSOCIAÇÃO BRASILEIRA DE ENSINO DE BIBLIOTECONOMIA E DOCUMENTAÇÃO. II Encontro Nacional de Ensino de Biblioteconomia e Ciência da Informação: relatório. Porto Alegre: ABEBD, 1989. 13p. Mimeografado.

ASSOCIAÇÃO BRASILEIRA DE ENSINO DE BIBLIOTECONOMIA E DOCUMENTAÇÃO. III Encontro Nacional de Ensino de Biblioteconomia e Ciência da Informação: relatório. Revista Brasileira de Biblioteconomia e Documentação, São Paulo, v. 26, n.1/2, p.145-151, 1993.

ASSOCIAÇÃO BRASILEIRA DE ENSINO DE BIBLIOTECONOMIAE DOCUMENTAÇÃO. Moderno profissional da informação: o perfil almejado pelos cursos de Biblioteconomia brasileiros. Porto Alegre: ABEBD, 1998. (Documentos ABEBD; 13).

BARBER, E. Informe sobre el Encuentro de Educación e Investigación en Bibliotecología, Archivología, Ciencia de la Información y Documentación de lberoamérica y el Caribe, 2000, Granada (España). In: ENCUENTRO DE DIRECTORES DE ESCUELAS DE BIBLIOTECOLOGÍA Y CIENCIA DE LA INFORMACIÓN DEL MERCOSUR, 4., ENCUENTRO DE DOCENTES DE ESCUELAS DE BIBLIOTECOLOGÍA Y CIENCIA DE LA
INFORMACIÓN DEL MERCOSUR, 3., 2000, Montevidéo: Universidad de La República, 2000. $6 \mathrm{p}$.

BRASIL. Lei no 9.394, de 20 de dezembro de 1996. Estabelece as diretrizes e bases da educação nacional. Diário Oficial da União, Brasília, v.134, n.248, 27 dez. 1996.

BRASIL. Ministério da Educação e do Desporto. Secretaria de Educação Superior. Proposta de diretrizes curriculares para os cursos de Biblioteconomia. Brasília: MEC/SESu, 2000. Disponível em: <http://www.mec.gov.br/sesu/ftp/curdiretriz/ informacao/dir.doc>. Acesso em: 19 fev. 2001.

BUARQUE, C. A aventura da universidade. São Paulo: UNESP, 1994.

CONFORTI, N; ARTAZA, C. H. La Bibliotecología: ciencia, técnica o tecnología. In: ENCUENTRO DE DIRECTORES DE ESCUELAS DE BIBLIOTECOLOGÍA Y CIENCIA DE LA INFORMACIÓN DEL MERCOSUR, 4., ENCUENTRO DE DOCENTES DE ESCUELAS DE BIBLIOTECOLOGÍA DEL MERCOSUR, 3, 2000 Montevideo. Actas... Montevideo: Universidad de la República, 2000. p.89-100.

CHUEQUE, M. G. et al. La inter y transdiciplinaridad: uma cuestión pendiente. In: ENCUENTRO DE 
DIRECTORES DE ESCUELAS DE BIBLIOTECOLOGÍA Y CIENCIA DE LA INFORMACIÓN DEL MERCOSUR, 4., ENCUENTRO DE DOCENTES DE ESCUELAS DE BIBLIOTECOLOGÍA DEL MERCOSUR, 3., 2000 Montevideo. Actas... Montevideo: Universidad de la República, 2000. p.89-119.

CUNHA, M. I. Relação ensino e pesquisa. In: VEIGA, I.P.A. Didática: o ensino e suas relações. 2.ed. Campinas: Papirus, 1996. p. 115-126.

CYSNE, F.P. Biblioteconomia: dimensão social e educativa. Fortaleza: UFC, 1993.

DEMO, P. Princípio científico e educativo. 2.ed. São Paulo: Cortez, 1991.

DEMO, P. Desafios modernos da educação. 6.ed. Petrópolis: Vozes, 1997.

DEMO, P. Educar pela pesquisa. 2.ed. Campinas: Autores Associados, 1997.

ENCONTRO DE DIRIGENTES DE CURSOS SUPERIORES EM BIBLIOTECONOMIA DO MERCOSUL, 1996, Porto Alegre. A formação profissional em Biblioteconomia no Mercosul. Porto Alegre: ABEBD, 1996. 3v.

ENCUENTRO DE DIRECTORES DE LOS CURSOS SUPERIORES DE BIBLIOTECOLOGÍA DEL MERCOSUR, 2., ENCUENTRO DE DOCENTES DE BIBLIOTECOLOGÍA Y CIENCIA DE LA INFORMACIÓN DEL MERCOSUR, 1997, Buenos Aires. La formación profesional en Bibliotecología y Ciencia de la Información en el Mercosur: acuerdos y recomendaciones. Buenos Aires: Universidad de Buenos Aires. Facultad de Filosofía y Letras, 1997. 15p.

ENCUENTRO DE DIRECTORES DE LAS ESCUELAS DE BIBLIOTELOGÍS DEL MERCOSUR, 3., ENCUENTRO DE DOCENTES DE LAS ESCUELAS DE BIBLIOTECLOGÍA DEL MERCOSUR, 2., 1998, Santiago (Chile). Formación de recursos humanos en el área de información en el Mercosur: compatibilización curricular; competencias del profesional de la información en el Marcosur. Santiago (Chile): Universidad Tecnológica Metropolitana, 1999.

ENCUENTRO DE DIRECTORES DE ESCUELAS DE BIBLIOTECOLOGÍA Y CIENCIA DE LA
INFORMACIÓN DEL MERCOSUR, 4., ENCUENTRO DE DOCENTES DE ESCUELAS DE BIBLIOTECOLOGÍA DEL MERCOSUR, 3., 2000, Montevideo (Uruguay). Actas... Montevideo: Universidad de la República, 2000.

ENCUENTRO DE DIRECTORES DE ESCUELAS DE BIBLIOTECOLOGÍA Y CIENCIA DE LA INFORMACIÓN DEL MERCOSUR, 5., ENCUENTRO DE DOCENTES DE ESCUELAS DE BIBLIOTECOLOGÍA DEL MERCOSUR, 4., 2001, San Lorenzo (Paraguai). Actas... Asunción: Universidad Nacional de Asunción, 2001.

ENCUENTRO DE DIRECTORES DE ESCUELAS DE BIBLIOTECOLOGÍA Y CIENCIAS DE LA INFORMACIÓN DEL MERCOSUR, 5., ENCUENTRO DE DOCENTES DE ESCUELAS DE BIBLIOTECOLOGÍA Y CIENCIAS DE LA INFORMACIÓN DEL MERCOSUR, 2001, San Lorenzo (Paraguai). Conclusões da área 6: Investigação. 2 f.

ENCUENTRO DE DIRECTORES DE ESCUELAS DE BIBLIOTECOLOGÍA Y CIENCIAS DE LA INFORMACIÓN DEL MERCOSUR, 5., ENCUENTRO DE DOCENTES DE ESCUELAS DE BIBLIOTECOLOGÍA Y CIENCIAS DE LA INFORMACIÓN DEL MERCOSUR, 2001, San Lorenzo (Paraguai). Talleres por areas. $2 f$.

ENCUENTRO DE EDUCADORES E INVESTIGADORES DE BIBLIOTECOLOGÍA, ARCHIVOLOGÍA Y CIENCIA DE LA INFORMACIÓN Y DOCUMENTACIÓN DE IBEROAMERICA Y EL CARIBE - EDIBCIC, 3., 1996, San Juan (Porto Rico). Informe de la Comisión de Pregrado. San Juan: Universidad de Puerto Rico, 1996. 4p.

ENCUENTRO DE EDUCADORES E INVESTIGADORES DE BIBLIOTECOLOGÍA, ARCHIVOLOGÍA Y CIENCIA DE LA INFORMACIÓN DE IBEROAMERICA Y EL CARIBE - EDIBCIC, 5., 2000, Granada (España). La formación de profesionales e investigadores de la información para la sociedad del conocimiento: actas del... Granada: Universidad de Granada. Facultad de Biblioteconomia y Documentación, 2000. 506p. 
FERNÁNDEZ, J.E. Dimensiones institucionales de la práctica de investigación em Ciencia de la Información. In: ENCUENTRO DE DIRECTORES DE ESCUELAS DE BIBLIOTECOLOGÍA Y CIENCIA DE LA INFORMACIÓN DEL MERCOSUR, 4., ENCUENTRO DE DOCENTES DE ESCUELAS DE BIBLIOTECOLOGÍA DEL MERCOSUR, 3., 2000. Montevideo (Uruguai). Actas... Montevideo: Universidad de la República, 2000. p.89, 316.

GUARIDO, M.D.M.; GUIMARÃES, J.A.C.; OLIVEIRA E.F.T. A importância da pesquisa na formação do profissional bibliotecário da Faculdade de Filosofia e Ciências da UNESP/Marília. Marília Uneso, 19--.

GUIMARÃES, J.A.C. Ensino de tratamento temático da informação nos cursos de Biblioteconomia do MERCOSUL: uma análise histórica dos encontros de diretores e docentes (1996-2000). [s.l.: s.n.], 2000.

GUIMARÃES J.A.C. Moderno profissional da informação: elementos para sua formação no Brasil. Transinformação, v.9, n.1, p.124/137, 1997.

GUIMARÃES, J.A.C. Ensino de Biblioteconomia no Brasil: uma perspectiva histórica dos encontros nacionais promovidos pela ABEBD. Cadernos da F.F.C. (Faculdade de Filosofia e Ciências da UNESP), Marília, v.4, n.1, p:68-81, 1995.

GUIMARÃES, J.A.C. Formação profissional no campo de informação no Brasil: algumas considerações acerca da LDB. In: SEMINÁRIO DE ESTUDOS DE INFORMAÇÃO DA UFF, 2., SEMINÁRIO DA ANCIB - REGIÃO SUDESTE, 1. 1998, Niterói, Anais... Niterói: NEINFO/UFF, 1998. p.47-51. CD-ROM.

GUIMARÃES, J.A.C. O profissional da informação sob o prisma de sua formação. In: VALENTIM, M.L.P. (Org.). Profissional da informação: formação, perfil e atuação profissional. São Paulo: Polis, 2000. Cap. 2, p:53-70.

LUCK, E.H.; RODRIGUES, M.E.F. III Encontro Nacional de Ensino de Biblioteconomia e Ciência da Informação: relato das participantes. Niterói, 1992. 21p.

MUELLER, S.P.M. Reflexões sobre a formação profissional para Biblioteconomia e sua relação com as demais profissões da informação. Transinformação, Campinas, v.1, n.2, 175-185, 1989.
PRIMER TALLER PARA LA ELABORACIÓN DE UN PLÁN CORDINADO DE ENTRENAMIENTO PARA PROFESIONALES DE INFORMACIÓN EN AMERICA LATINA Y EL CARIBE, 1994, Belo Horizonte. In: BIBLIOS 2000. Belo Horizonte: ABMG 1995. v.2, p:211-232. Informe final.

PROPOSTA DE REESTRURAÇÃO CURRICULAR. Marília: UNESP, 1996.

RAMIREZ, E.; AÑORVE, M.; GRANIEL, M.R. Reunión de Investigadores e Educadores de Iberoamerica y el Caribe en el area de la Bibliotecología y Ciencia de la Información. México; UNAM/CUIB, 1996.

RODRIGUES, M.E.F. Ensino com pesquisa: uma nova concepção pedagógica para as áreas de Biblioteconomia e Ciência da Informação. In: ENCUENTRO DE DIRECTORES DE ESCUELAS DE BIBLIOTECOLOGÍA Y CIENCIA DE LA INFORMACIÓN DEL MERCOSUR, 4., ENCUENTRO DE DOCENTES DE ESCUELAS DE BIBLIOTECOLOGÍA DEL MERCOSUR, 3., 2000 Montevideo. Actas... Montevideo: Universidad de la República, 2000. p.89-323.

RODRIGUES, M.E.F. A pesquisa como estratégia pedagógica para competência profissional. In: ENCUENTRO DE DIRECTORES Y SEGUNDO DE DOCENTES DE LAS ESCUELAS DE BIBLIOTECOLOGía DEL MERCOSUR, 3., 1998, Santiago de Chile. Actas ... Santiago de Chile: Universida Tecnológica Metropolina; Facultad de Administracion y Economia. Escuela de Bibliotecología, 1999. p.41-44.

SABELLI, M. United colors of Information Science: entre deifniciones y creatividad em los tiempos de cambio. In: ENCUENTRO DE DIRECTORES DE ESCUELAS DE BIBLIOTECOLOGÍA Y CIENCIA DE LA INFORMACIÓN DEL MERCOSUR, 4., ENCUENTRO DE BIBLIOTECOLOGÍA DEL MERCOSUR, 3., 2000 Montevideo (Uruguai). Actas... Montevideo: Universidad de la República. 2000. p.89 -162.

SANTOS, J.P. O ensino de Biblioteconomia no Brasil: propostas de integração e harmonização curricular. São Paulo: APB, 1997. (Ensaios APB; 41). 
SANTOS, J.P.; NEVES, I.C.B. A formação do moderno profissional da informação: relatório técnico. In: ENCONTRO NACIONAL DE ENSINO DE BIBLIOTECONOMIA E CIENCIA DA INFORMAÇÃO, 5., 1998, São Carlos. Porto Alegre: ABEBD, 1998. 11p.

SANTOS, J.P.; NEVES, I.C.B. Harmonização curricular em Biblioteconomia no MERCOSUL. Porto Alegre: ABEBD, 1998. 21p. Relatório técnico do II Encontro de Dirigentes dos Cursos Superiores de Biblioteconomia dos Países do MERCOSUL e I Encontro de Docentes de Biblioteconomia e Ciência da Informação do MERCOSUL. Buenos Aires, 27-29 nov. 1997.

SANTOS, J.P. A ABEBD e o ensino de Biblioteconomia do MERCOSUL: relatório de atividades da gestão 1997-1998. Porto Alegre: ABEBD, 1998. (Documentos ABEBD, 11)

SANTOS, J.P. O moderno profissional da informação: o bibliotecário e seu perfil face aos novos tempos. Informação \& Informação, Londrina, v.1, n.1, p.5-13, 1993.
SANTOS, J.P. Reflexões sobre currículo e legislação na área de Biblioteconomia. Porto Alegre: ABEBD, 1998. (Documentos ABEBD, 14).

SILVA, L.G.F.; KRUEL, I.R.P.; SANTOS, J. P. Ensino de Biblioteconomia no Brasil: problemas e perspectivas. Porto Alegre: Associação Brasileira de Ensino de Biblioteconomia e Documentação, 1990.

SOUZA, F.C. O ensino de Biblioteconomia no contexto brasileiro. Florianópolis: UFSC, 1990.

TALLER REGIONAL PARA LA ELABORACIÓN DE UN PLAN COORDINADO DE ENTRENAMIENTO PARA PROFESIONALES DE LA INFORMACIÓN EN AMERICA LATINA Y EL CARIBE, 1., 1994, Belo Horizonte. Informe final. In: BIBLIOS 2000: Anais... Belo Horizonte: Associação de Bibliotecários de Minas Gerais; Escola de Biblioteconomia da UFMG, 1995. v.3, p:211-237.

VALENTIM, M.L.P. Profissional da informação: formação, perfil e atuação profissional. São Paulo: Polis, 2000. p.7-30. 
